\title{
Hepatocellular carcinoma in Central Europe: prognostic features and survival
}

\author{
M Schöniger-Hekele, C Müller, M Kutilek, C Oesterreicher, P Ferenci, A Gangl
}

\begin{abstract}
Background and aims-We investigated the influence of baseline characteristics of patients with hepatocellular carcinoma (HCC) on prognosis and developed a multivariate Cox model predicting survival. All patients were from Central Europe. Methods-All 245 patients seen at the Department of Gastroenterology and Hepatology at the University of Vienna, Austria, from July 1991 to March 1998 were included in this retrospective study. Nineteen different clinical characteristics and survival time from date of diagnosis were noted. Factors determining survival time were analysed by univariate and multivariate analysis using Cox proportional hazard regression models and a new classification model was constructed. The validity of this model was tested on an independent group of 89 patients, seen from April 1998 to September 1999.
\end{abstract}

Results-Median survival in patients with HCC was 8.0 months. In a multivariate analysis bilirubin ( $>2 \mathrm{mg} / \mathrm{dl})$, portal vein thrombosis, prothrombin time $(<70 \%)$, alpha fetoprotein $(>180 \mu \mathrm{g} / \mathrm{l})$, tumour mass $>50 \%$, and enlarged lymph nodes were independent predictors of survival. A newly constructed Cox proportional hazard model (Vienna survival model for HCC=VISUM-HCC) identified three disease stages with different durations of survival (median survival stage 1, 15.2 months; stage 2, 7.2 months; and stage 3 , 2.6 months; $p=0.00001)$. Applying the VISUM-HCC survival model to patients in Okuda stage 2 identified subgroups with an excellent and very poor prognosis for which different treatment modalities should be offered.

Conclusions-Our patients with HCC had a poor median survival of eight months. Six easily measurable clinical variables were significant predictors of survival in patients with HCC. The new VISUM-HCC survival model may be useful for stratifying patients with HCC for various clinical treatment modalities.

(Gut 2001;48:103-109)

Keywords: hepatocellular carcinoma; clinical presentation; prognostic model

Dr C Müller, Universitätsklinik für In Abteilung Gastroenterologie und Hepatologie, Währinger Gürtel 18-20, A-1090 Wien, Vienna, Austria.

christian.muller@akh-wien.ac.at

Accepted for publication 22 June 2000

Hepatocellular carcinoma (HCC) as a sequela of chronic liver disease is increasingly seen in industrialised nations. ${ }^{1}$ A number of studies analysed the influence of demographic characteristics, tumour related factors such as size or number of nodules, and factors related to liver function on survival. Okuda and colleagues ${ }^{2}$ proposed a widely used classification scheme of HCC which includes serum bilirubin, serum albumin, tumour mass, and ascites as parameters. The International Union against Cancer's (UICC) TNM classification considering only tumour related factors has poor prognostic value, ${ }^{3}$ mostly because liver function is not taken into account. These prognostic models were developed many years ago and were not modified. However, the epidemiological and clinical basis of these models has changed over time. The aetiology of the underlying liver disease leading to cirrhosis and HCC varies both in time and with geographic area: in Western industrial countries and in Japan, hepatitis B virus related $\mathrm{HCC}$ is decreasing ${ }^{45}$ whereas hepatitis C virus (HCV) associated HCC is increasing. ${ }^{67}$ In China, aflatoxin $\mathrm{B} 1$ is an important cofactor of hepatic carcinogenesis, often associated with p53 mutations. ${ }^{8}{ }^{9}$ The geographic variation of HCC is also reflected by younger age of patients from South East Asia and higher prevalence of chronic viral hepatitis as opposed to a more dominant role of chronic alcoholic liver disease in Western countries. Furthermore, overall incidence rates are changing, showing a rise in the rate of HCC in the USA ${ }^{1}$ and Europe. ${ }^{10}{ }^{11}$ Also, treatment options and outcomes vary considerably ${ }^{12}$ and change over time. For example, surgery is a therapeutic option considered more often in South East Asian patients. ${ }^{12-14}$ As data collected in one region may not be representative of other areas, survival estimates derived from baseline clinical data must be collected regionally to account for these variables. In addition, increased screening efforts in recent years to detect tumours of a smaller size $e^{15}$ may explain differences in clinical presentation, epidemiological features, and survival in different parts of the world.

In this study a prognostic model was established for European patients based on baseline data obtained by 245 consecutive patients with HCC seen at a tertiary referral centre at a university clinic. Univariate and multivariate regression analysis was used to define independent prognostic factors present at the time of diagnosis. Those factors were incorporated into a new Cox regression model describing survival of our patient population.

Abbreviations used in this paper: HCC hepatocellular carcinoma; $\mathrm{HCV}$, hepatitis $\mathrm{C}$ virus;

HBsAg, hepatitis B virus surface antigen; PTV, portal

vein thrombosis; PT, prothrombin time; AFP, $\alpha$ fetoprotein; RRD, relative risk of death; UICC, International Union against Cancer. 
This model was confirmed by testing on an independent group of patients with HCC.

\section{Patients and methods}

PATIENTS

Two groups of patients were included in the study. The first group ("model group") consisted of all 245 (58 females (23.7\%), 187 males $(76.3 \%)$ ) patients of Caucasian origin with HCC seen at the Department of Gastroenterology and Hepatology, University of Vienna from July 1991 to March 1998. The demographic and clinical characteristics of this group are shown in table $1 ; 1.6 \%$ of our patients were of non-European origin.

Liver cirrhosis was diagnosed either by histology or by the typical combination of clinical, laboratory, and gastroscopic findings together with the presence of ultrasound verified ascites strongly suggestive of liver cirrhosis. Liver biopsy was available in 191 $(78 \%)$ patients. Patients were grouped according to the following diagnostic characteristics: hepatitis B virus surface antigen ( $\mathrm{HBsAg}$ ) positivity, anti-HCV positivity, and chronic alcoholism (>60 g ethanol/day); haemochromatosis was diagnosed either by histological assessment of liver biopsy or by determination of the C282Y mutation of the HFE gene. Death was assessed by examining the Austrian national death registry.

An independent second group of patients included all 89 patients (14 females (15.7\%), 75 males $(84.3 \%)$ ) seen at our institution after the model group. In none of the 19 baseline parameters tested was a statistically significant difference found between the model and testing groups (see table 1).

DIAGNOSIS OF HCC AND STAGING CLASSIFICATION As a tertiary referral centre we do not recruit our patients through a surveillance programme for HCC; diagnosis in most of our patients was a chance finding during ultrasound examina-

Table 1 Patient characteristics and aetiology at time of diagnosis of hepatocellular carcinoma

\begin{tabular}{|c|c|c|c|c|}
\hline & \multicolumn{2}{|c|}{ Model group } & \multicolumn{2}{|c|}{ Testing group } \\
\hline & Number & Percentage & Number & Percentage \\
\hline $\mathrm{n}$ & 245 & & 89 & \\
\hline Median age (y) & 63.3 & & 61.1 & \\
\hline Female median age & 66.3 & & 61.1 & \\
\hline Male median age & 61.3 & & 64.1 & \\
\hline \multicolumn{5}{|l|}{ Sex distribution } \\
\hline Male & 187 & 76.3 & 75 & 84.3 \\
\hline Female & 58 & 23.7 & 14 & 15.7 \\
\hline Sex ratio $(M: F)$ & $3.2: 1$ & & $5.4: 1$ & \\
\hline Liver cirrhosis & 212 & 86.5 & 79 & 88.8 \\
\hline \multicolumn{5}{|l|}{ Child-Pugh-stage } \\
\hline A & 84 & 34.3 & 38 & 42.7 \\
\hline B & 93 & 38.0 & 28 & 31.5 \\
\hline $\mathrm{C}$ & 35 & 14.3 & 13 & 14.6 \\
\hline No liver cirrhosis or undetermined & 33 & 13.5 & 10 & 11.2 \\
\hline Chronic viral hepatitis & 118 & 48.2 & 36 & 40.5 \\
\hline HBsAg+/anti-HCV- & 24 & 9.8 & 7 & 7.9 \\
\hline Anti-HCV+/HBsAg- & 90 & 36.7 & 28 & 3.5 \\
\hline $\mathrm{HBsAg}+/$ anti-HCV+ & 4 & 1.6 & 1 & 1.1 \\
\hline $\begin{array}{l}\text { Non-viral aetiology (HBsAg-/ } \\
\text { anti-HCV-) }\end{array}$ & 127 & 51.8 & 53 & 59.5 \\
\hline Chronic alcoholism & 86 & 35.1 & 38 & 42.7 \\
\hline Cryptogen & 28 & 11.4 & 9 & 10.1 \\
\hline Haemochromatosis & 10 & 4.1 & 4 & 4.5 \\
\hline Other causative factors & 3 & 1.2 & 2 & 2.2 \\
\hline
\end{tabular}

There were no statistically significant differences between the two groups. tion or triggered by symptoms. The diagnosis of HCC was confirmed by liver biopsy in 191 (78\%) patients in the model group; in patients without histological confirmation of HCC $(22 \%)$, diagnosis was made by high $\alpha$ fetoprotein (AFP) values $(>700 \mu \mathrm{g} / \mathrm{l})$ and demonstration of a tumour by ultrasonography or computed tomography scan. Grading information according to Edmondson and Steiner's $^{16}$ classification was available in 167 patients. When histological diversity was observed in a tumour, the higher grade according to the classification system was taken to be the overall grade. Tumours were classified according to the TNM classification of the $\mathrm{UICC}^{17}$ and according to the staging system proposed by Okuda. ${ }^{2}$ Tumour mass was estimated using computed tomography scans according to Okuda. ${ }^{2}$ Enlarged lymph nodes were defined as lymph nodes greater than $1 \mathrm{~cm}$ in diameter at the portal, coeliac, retrocrurial, or retroperitoneal lymph node station. ${ }^{18}$ Portal vein thrombosis was diagnosed either by ultrasound or contrast enhanced computed tomography scans.

The treatment modalities in the model group were: liver resection $(n=34$; median survival 20.7 months), liver transplantation ( $n=38$; median survival 21.0 months), chemotherapy ( $\mathrm{n}=38$; median survival 8.0 months), and 145 patients received palliative care (median survival 4.4 months). Although patients undergoing surgery or liver transplantation had significantly longer survival (log rank test, $\mathrm{p}<0.01)$ than patients receiving chemotherapy or palliative care, we do not report these differences as treatment induced because the patient's underlying clinical state was clearly a major determinant of the mode of therapy chosen and no randomised study has shown this to significantly prolong survival. ${ }^{19-21}$ Excluding the small number of patients with liver transplantation from our study population did not change survival compared with the overall group (log rank test, NS).

\section{STATISTICS}

Descriptive statistics

Data are presented as median (95\% confidence interval). $\chi^{2}$ tests for nominal data and $t$ tests for numerical data were used to compare baseline characteristics. Reported p values are two sided and $p$ values $<0.05$ were considered significant. The Kaplan-Meier method ${ }^{22}$ was used to determine patient survival and the log rank test to compare survival between subgroups.

\section{Regression analysis}

Univariate and multivariate regression analyses were performed using the Cox proportional hazard regression model ${ }^{2324}$ to determine the effect of various variables on survival. Nineteen different variables were chosen to be included in the univariate analysis: bilirubin, prothrombin time (PT), ascites, albumin, AFP, portal vein thrombosis (PVT), enlarged lymph nodes, distant metastases, unilobar/bilobar, tumour $>50 \%$, diameter $>2 \mathrm{~cm}$, number of tumour nodules, histological grading according to Edmondson and Steiner, HBsAg positivity, 
age, smoking, sex, alcohol, and anti-HCV positivity. When used as continuous variables, bilirubin and AFP were introduced after logarithmic transformation because of the skewed distribution. When dichotomous variables were used instead of continuous variables, the cut off level chosen was its median value. When the median value was close to the normal limit, the latter was used as a cut off. Four clinical variables (bilirubin, albumin, AFP, PT) were assessed both as continuous and dichotomous variables. The assumption of proportional hazards was examined graphically by observing a constant vertical difference between plots of log integrated hazard against time for various levels of each variable. ${ }^{25}$ Significant variables in univariate analysis were included in Cox's multivariate regression analysis and the backward elimination method was used.

\section{Evaluation of the survival model}

To evaluate our survival model, we calculated the relative risk of death (RRD) for each patient using the significant prognostic variables obtained in the multivariate analysis. The following equation was used:

$$
\lambda_{\mathrm{i}(\mathrm{t})} / \lambda_{0(\mathrm{t})}=\exp \left(\beta_{1}\left(\mathrm{x}_{1 \mathrm{i}}-\mathrm{x}_{1}\right)+\ldots+\beta_{\mathrm{p}}\left(\mathrm{x}_{\mathrm{pi}}-\mathrm{x}_{\mathrm{p}}\right)\right)
$$

where $\lambda_{\mathrm{i}(t)}$ is the hazard rate for survival of a particular patient at time $t, \lambda_{o(t)}$ is the hazard

Table 2 Median survival time of patients with hepatocellular carcinoma

\begin{tabular}{|c|c|c|c|}
\hline Parameter & $n$ & $\begin{array}{l}\text { Median survival ( } 95 \% \\
\text { confidence interval) }\end{array}$ & Log rank test \\
\hline Overall & 245 & $8.0(6.4-11.9)$ & \\
\hline Female & 58 & $8 \quad(6.1-12.0)$ & $\mathrm{p}=0.6289$ \\
\hline Male & 187 & $8.6(5.9-15.3)$ & \\
\hline Underlying cirrhosis & 212 & $6.8(5.5-9.9)$ & $\mathrm{p}=0.0024$ \\
\hline No liver cirrhosis & 33 & $21.3(13.9-62.5)$ & \\
\hline \multicolumn{4}{|l|}{ Child-Pugh stage } \\
\hline A & 84 & $12.0(9.4-17.3)$ & \multirow[t]{3}{*}{$\mathrm{p}=0.0001$} \\
\hline B & 93 & $6.8(4.5-11.4)$ & \\
\hline C & 35 & $1.9(1.5-3.0)$ & \\
\hline \multicolumn{4}{|l|}{ Aetiology } \\
\hline Chronic alcoholism & 86 & $6.8(5.1-11.4)$ & \multirow[t]{4}{*}{$\mathrm{p}=0.1309$} \\
\hline Hepatitis B & 24 & $3.4(2.8-6.0)$ & \\
\hline Hepatitis C & 90 & $11.0(6.7-15.3)$ & \\
\hline Haemochromatosis & 10 & $18.7(16.0-\star)$ & \\
\hline \multicolumn{4}{|l|}{ Edmondson-Steiner } \\
\hline G1 & 40 & $13.3(6.1-17.3)$ & \multirow[t]{3}{*}{$\mathrm{p}=0.0666$} \\
\hline G2 & 83 & $11.1(7.5-20.9)$ & \\
\hline G3 & 44 & $4.7(2.8-11.0)$ & \\
\hline \multicolumn{4}{|l|}{ Okuda } \\
\hline Stage 1 & 40 & $15.8(12.7-37.3)$ & \multirow[t]{3}{*}{$\mathrm{p}=0.0001$} \\
\hline Stage 2 & 161 & $10.2(7.5-13.9)$ & \\
\hline Stage 3 & 44 & $2.7(2.0-4.3)$ & \\
\hline \multicolumn{4}{|l|}{ TNM classification } \\
\hline Stage 3 & 64 & $12.8(7.6-25.3)$ & \multirow{2}{*}{$\mathrm{p}=0.0028$} \\
\hline Stage 4 & 152 & $5.8(4.3-7.2)$ & \\
\hline \multicolumn{4}{|l|}{ VISUM classification } \\
\hline Stage 1 & 131 & $15.2(12.4-27.1)$ & \multirow[t]{3}{*}{$\mathrm{p}=0.0001$} \\
\hline Stage 2 & 63 & $7.2(4.4-12.7)$ & \\
\hline Stage 3 & 51 & $2.6(2.0-3.4)$ & \\
\hline \multicolumn{4}{|l|}{ Age distribution } \\
\hline$<30$ & 2 & 37.3 & \\
\hline $30-40$ & 4 & 5.6 & \\
\hline $40-50$ & 23 & 8.6 & \\
\hline $50-60$ & 72 & 11.0 & \\
\hline $60-70$ & 92 & 10.4 & \\
\hline $70-80$ & 48 & 5.3 & \\
\hline$>80$ & 4 & 29.2 & \\
\hline \multicolumn{4}{|l|}{ AFP distribution } \\
\hline $0-7$ & 45 & $13.9(10.7-27.1)$ & \multirow[t]{5}{*}{$\mathrm{p}=0.0179$} \\
\hline $7-20$ & 34 & $10.2(6.1-22.3)$ & \\
\hline $20-100$ & 36 & $11.9(4.6-17.0)$ & \\
\hline $100-500$ & 40 & $8.4(4.2-15.3)$ & \\
\hline$>500$ & 81 & $5.4(3.7-8.0)$ & \\
\hline \multicolumn{4}{|l|}{ PVT } \\
\hline Yes & 56 & $4.0(2.8-6.0)$ & \multirow[t]{2}{*}{$\mathrm{p}=0.0007$} \\
\hline No & 162 & $9.6(7.9-15.3)$ & \\
\hline
\end{tabular}

PTV, portal vein thrombosis; AFP, $\alpha$ fetoprotein. calculated at the average values of the variables in the model, $\beta_{1}$ to $\beta_{\mathrm{p}}$ are the regression coefficients of the variables, $\mathrm{x}_{1 \mathrm{i}}$ to $\mathrm{x}_{\mathrm{pi}}$ are the values of the variables of a particular patient, and $x_{1}$ to $x_{p}$ are the mean values of these variables from all patients. ${ }^{2635}$ Variables were introduced as dichotomous variables. The higher the values for RRD, the worse is the prognosis; lower values indicate a better prognosis.

A complete set of variables is required for this analysis. Therefore, we replaced missing data by mean values obtained in the whole series so as not to reduce the number of patients.

The predictive power of the model was tested in an independent group ("testing group") of patients. After the RRD for each of the patients in the model group was calculated the model group was divided into three subgroups of similar size but identical risk. Survival curves for these subgroups were estimated using the Kaplan-Meier method. Regression coefficients of the significant variables obtained in the multivariate analysis of the model group were also used to compute the RRD in the testing group of patients. The testing group was also divided into three subgroups with identical risk, as defined by the same RRD boundaries as in the model group and survival curves were calculated as described above. Validation of the final model was assessed by comparing the corresponding survival curves of the model group and the testing group of patients. If there were no statistically significant differences between the corresponding survival curves, the validity of the model was confirmed. Survival of different prognostic stages was compared using the log rank test.

All statistical calculations were done using Statistica for Windows (version 5.1, StatSoft, Inc., USA 1997).

\section{Results}

PATIENT CHARACTERISTICS (TABLE 1)

Our study population consisted of typical Western European patients. Chronic HCV infection was the underlying aetiology in one third of our patients, another third presented with chronic alcoholism, and only $10 \%$ had chronic hepatitis B virus infection. Liver cirrhosis was present in $90 \%$ of patients with HCC; only a small percentage had no liver cirrhosis. Our patients presented in an advanced stage of disease with a poor median survival of only eight months (see table 1 ).

MEDIAN SURVIVAL (TABLE 2)

Overall median survival was 8.0 months (fig $1 \mathrm{~A})$ and did not differ between male and female patients. A total of $202(82.45 \%)$ patients had died by the time of analysis. Survival of HCC patients without liver cirrhosis was longer than that of patients with liver cirrhosis (21.3 v 6.8 months; $\mathrm{p}=0.0024)$. Within the group of cirrhotic patients, median survival rates in Child-Pugh stages $\mathrm{A}, \mathrm{B}$, and $\mathrm{C}$ were 12.0, 6.8, and 1.9 months, respectively (A $v \mathrm{~B}, \mathrm{p}=0.04608$; $\mathrm{B} v \mathrm{C}, \mathrm{p}=0.00003$ ) (fig 1B). Patients with chronic hepatitis B had the worst 

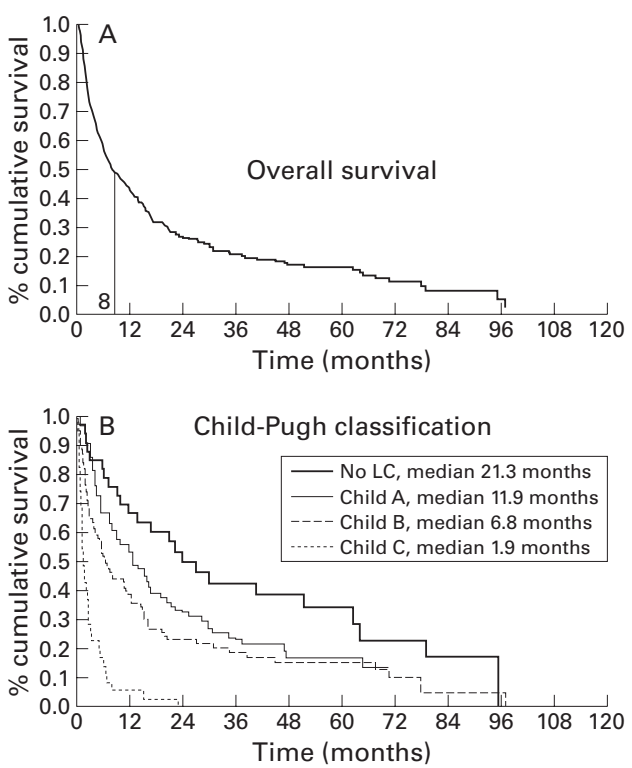

Figure 1 (A) Cumulative survival rate for all 245 patients included in the study. Median survival was 8.0 months. (B) Cumulative survival of patients with hepatocellular carcinoma with cirrhosis Child stage $A$ $(n=84)$, Child stage $B(n=93)$, and Child stage $C(n=35)$, and without liver cirrhosis (No LC) $(n=33)$. Survival was significantly different between patients with and without cirrhosis (log rank test, $p=0.00041$ ).

median survival (3.4 months), less than that of patients with chronic alcoholism (6.8 months) or hepatitis $\mathrm{C}$ (11.0 months). G3 grading in the Edmondson-Steiner classification (table 2), higher staging according to the classifications of Okuda (fig 2A, table 2) or TNM (table 2),
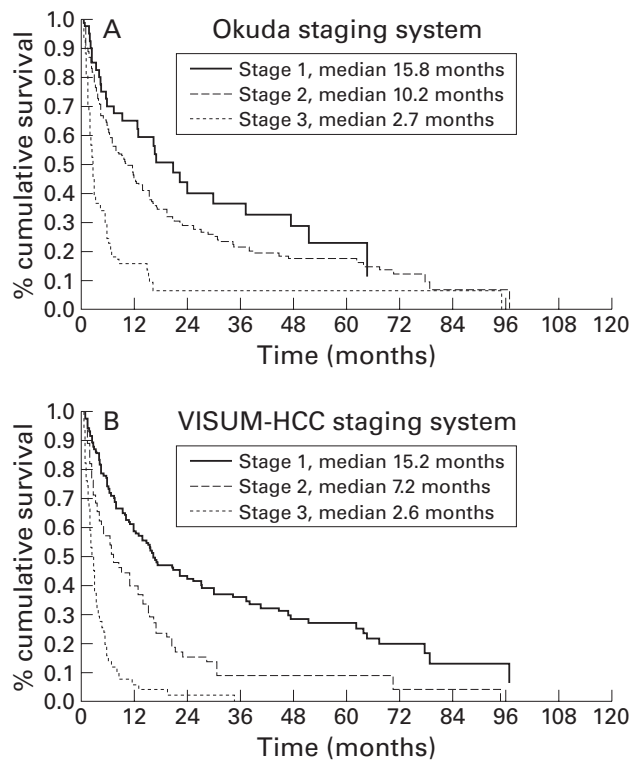

Figure 2 (A) Cumulative survival of patients with hepatocellular carcinoma (HCC) $(n=245)$ grouped according to Okuda stages: stage $1(n=40)$, stage 2 $(n=161)$, and stage $3(n=44)$. Survival was statistically different between stages 2 and 3 (log rank test, $p=0.0001$ ) but not between stages 1 and 2 (log rank test, $p=0.06331$ ).

(B) Cumulative survival rate of patients grouped according to the newly developed staging system VISUM-HCC, incorporating the six significant predictive variables (bilirubin $>2 \mathrm{mg} / \mathrm{dl}$, prothrombin time $<70 \%$, portal vein thrombosis, tumour mass $>50 \%$, enlarged lymph nodes, $\alpha$ fetoprotein $>125 \mathrm{kU} / \mathrm{l})$, as determined by multivariate analysis.
Table 3 Prognostic significance of variables in the univariate analysis

\begin{tabular}{rlcl}
\hline & Variable included & $\begin{array}{c}\text { Regression } \\
\text { coefficient }(\beta)\end{array}$ & p Coefficient \\
\hline 1 & Bilirubin $(<2 \mathrm{mg} / \mathrm{dl})$ & 0.644192 & 0.000016 \\
2 & PT $(<70 \%)$ & 0.621770 & 0.000077 \\
3 & Ascites (yes-no) & 0.591207 & 0.000126 \\
4 & Albumin (<3.5g/dl) & 0.507730 & 0.000635 \\
5 & PVT & 0.545117 & 0.000901 \\
6 & AFP (<125 kU/l) & 0.475678 & 0.001034 \\
7 & Enlarged lymph nodes & 0.495509 & 0.001757 \\
8 & Distant metastases & 0.492607 & 0.002174 \\
9 & Unilobar/bilobar & -0.005126 & 0.025371 \\
10 & Tumour $>50 \%($ yes-no) & 0.318607 & 0.026102 \\
11 & Diameter $(>2$ cm) & -0.005125 & 0.029782 \\
12 & No of tumour nodules & -0.004821 & 0.039713 \\
13 & Edmondson-Steiner & 0.223954 & 0.079851 \\
14 & HBV (HBsAg+) & 0.363311 & 0.109207 \\
15 & Age & 0.010530 & 0.127132 \\
16 & Smoking & 0.227728 & 0.149910 \\
17 & Sex & -0.081306 & 0.631941 \\
18 & Alcohol & 0.000294 & 0.835254 \\
19 & HCV (anti-HCV+) & 0.006705 & 0.963396 \\
\hline
\end{tabular}

HCV, hepatitis C virus; HBV, hepatitis B virus; HBsAg, hepatitis B virus surface antigen; PTV, portal vein thrombosis; PT, prothrombin time; AFP, $\alpha$ fetoprotein.

and the presence of PVT (table 2) were associated with a lower median survival. The overall median survival rate was $41.2 \%$ at one year, $26.6 \%$ at two years, $22.9 \%$ at three years, $18.2 \%$ at four years, and $15.9 \%$ at five years.

FACTORS AFFECTING SURVIVAL

Univariate analysis (table 3)

Using univariate analyses the following 12 clinical variables had significant influence on survival (table 3): bilirubin $<2 \mathrm{mg} / \mathrm{dl}$, PT $<70 \%$, ascites, albumin $<3.5 \mathrm{~g} / \mathrm{dl}$, PVT, AFP $<180 \mu \mathrm{g} / \mathrm{l}$, enlarged lymph nodes, distant metastases, unilobar/bilobar, tumour $>50 \%$ of liver mass, tumour diameter $>2 \mathrm{~cm}$, and number of tumour nodules. In contrast, in univariate analysis, sex, age, smoking, HBsAg positivity, anti-HCV positivity, alcoholism, and histological grading did not significantly influence survival.

Multivariate analysis (table 4)

The 12 significant baseline parameters determined by univariate analysis were included in a multivariate Cox regression analysis. Variables were selected using backward elimination. Six parameters remained significant independent predictors of survival: bilirubin $<2 \mathrm{mg} / \mathrm{dl}$, PVT, PT $<70 \%$, AFP $<180 \mu \mathrm{g} / 1$, tumour mass $>50 \%$ of liver mass, and enlarged lymph nodes (table 4) These variables were used as parameters in our model.

VISUM-HCC MODEL (TABLE 5)

The six significant variables were applied to construct a new survival model. We scored the variables either 0 (absent) or 1 (present) to simplify the practical use of the new model (table 5). In our new model, designated Vienna survival model for HCC (VISUM-HCC), stage 1 was defined as $0-2$ points, stage 2 as 3 points, and stage 3 as $4-6$ points. Survival was different between the three stages (fig 2B) with a median survival of 15.2 months in stage 1 , 7.2 months in stage 2 , and 2.6 months in stage 3 (log rank test, $\mathrm{p}=0.00021$ stage $1 v$ stage 2 and $\mathrm{p}=0.00002$ stage $2 v$ stage 3 ). 
Table 4 Significant prognostic variables on survival: multivariate analysis with dichotomous variables

\begin{tabular}{llllll}
\hline \multirow{2}{*}{ model } & \multirow{2}{*}{$\mathrm{d}$} & p Model & Variables included & $\begin{array}{l}\text { Regression } \\
\text { coefficient }(\beta)\end{array}$ & $p$ Coefficient \\
\hline \multirow{2}{*}{60.7090} & \multirow{2}{*}{0.00000} & Bilirubin $(<2 \mathrm{mg} / \mathrm{dl})$ & 0.557808 & 0.000351 \\
& & $\mathrm{PVT}$ & 0.550046 & 0.001098 \\
& & $\mathrm{PT}(<70 \%)$ & 0.520451 & 0.001441 \\
& & & $\mathrm{AFP}(<125 \mathrm{kU} / \mathrm{l})$ & 0.411822 & 0.005211 \\
& & & Tumour $>50 \%$ (yes-no) & 0.332785 & 0.023364 \\
& & Enlarged lymph nodes & 0.354986 & 0.029949 \\
\hline
\end{tabular}

PTV, portal vein thrombosis; PT, prothrombin time; AFP, $\alpha$ fetoprotein.

Table 5 VISUM-HCC: Vienna survival model for hepatocellular carcinoma

\begin{tabular}{lll}
\hline & \multicolumn{2}{l}{ Points } \\
\cline { 2 - 3 } Parameter & 0 & 1 \\
\hline Bilirubin $(\mathrm{mg} / \mathrm{dl})$ & $\leqslant 2$ & $>2$ \\
PT $(\%)$ & $>70$ & $\leqslant 70$ \\
AFP $(\mathrm{kU} / 1)$ & $\leqslant 125$ & $>125$ \\
Tumour $>50 \%$ & $\leqslant 50 \%$ & $>50 \%$ \\
Enlarged lymph nodes & No & Yes \\
PVT & No & Yes \\
& & \\
Stage $1: 0-2$ points & & $\Sigma$ points \\
Stage $2: 3$ points & & \\
Stage 3: $4-6$ points & & Stage $^{\star}:$ \\
\hline
\end{tabular}

PTV, portal vein thrombosis; PT, prothrombin time; AFP, $\alpha$ fetoprotein.

`The sum of the points ( $\Sigma$ points) gives the VISUM-HCC stage of the patient.

EVALUATION OF THE SURVIVAL MODEL

We evaluated our model by comparing survival, as predicted by the model group, with survival of patients in the testing group. The $\mathrm{RRD}$, predicted by the six independent parameters found in the multivariate analysis, was calculated for each patient according to the following equation detailed in the methods section:

$\lambda_{\mathrm{i}(\mathrm{t})} / \lambda_{0(\mathrm{t})}=\exp [0.557808 \times($ bilirubin -0.41$)$

$+0.520451 \times(\mathrm{PT}-0.61)+0.550046 \times$

$(\mathrm{PVT}-0.23)+0.411822 \times(\mathrm{AFP}-0.5)$

$+0.332785 \times($ tumour $>50 \%-0.4)+0.354986$

$\times($ enlarged lymph nodes -0.24$)]$

In this equation, all variables were introduced as dichotomous variables: bilirubin $(<2$ $\mathrm{mg} / \mathrm{dl}=0, \geqslant 2 \mathrm{mg} / \mathrm{dl}=1$ ), prothrombin time $(<70 \%=1, \geqslant 70 \%=0)$, enlarged lymph nodes (absent $=0$, present $=1)$, PVT (absent $=0$, present $=1)$, tumour mass $>50 \% \quad($ no $=0$, yes=1), and AFP $(<180=0, \geqslant 180=1)$. The model group was divided into three subgroups of similar size and consisted of 82,81 , and 82 patients, respectively; this resulted in RRD of $<0.7781,0.7781-1.2597$, and >1.2597. Regression coefficients obtained in the model group were used to calculate the RRD for each

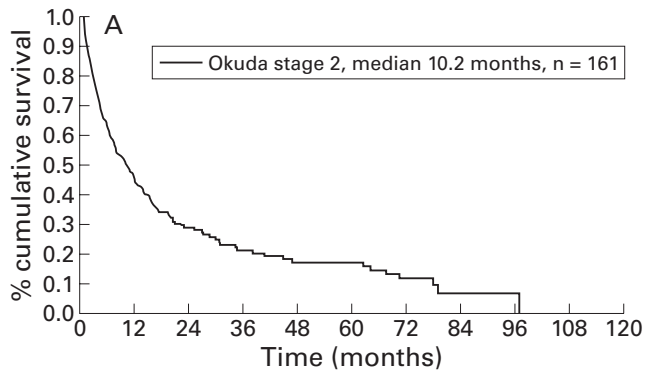

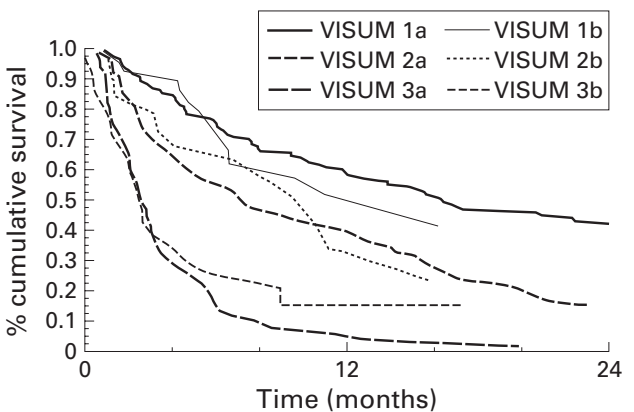

Figure 3 Survival curves of patients stratified according to VISUM-HCC criteria between the model group (group $A$ ) and the testing group (group B); no significant difference was found.

patient in the testing group; the testing group was also divided into three subgroups with identical boundaries as in the model group. These three subgroups consisted of 34, 15, and 40 patients, respectively. Survival curves were estimated according to Kaplan-Meier and corresponding curves were compared using the log rank test. Differences in survival of the corresponding groups with identical RRD in the model group and the testing group were not statistically significant, confirming the validity of the model (the overall median survival rate was $41.2 \%$ at one year in the model group and $36 \%$ at one year in the testing group; NS). Figure 3 compares survival curves of patients stratified according to VISUMHCC criteria between the model group and the testing group; no significant difference was found.

\section{COMPARISON OF VISUM-HCC AND OKUDA}

STAGING SYSTEM

Figure 2 shows cumulative survival according to Okuda stages and VISUM-HCC staging system. Survival differed significantly between VISUM-HCC stages 1, 2, and 3, respectively, whereas in Okuda stages only survival in stages 2 and 3 was statistically different but not between stages 1 and 2 . In fig 4 the survival curve of patients with Okuda stage 2 (fig 4A) is shown. To further subdivide patients into groups with different survivals, we applied VISUM-HCC criteria to patients in Okuda stage 2 (fig 4B); this divided Okuda stage 2 into three subgroups with significantly different survivals ( $\log$ rank test, $\mathrm{p}=0.0000$ ). Thus patients in Okuda stage 2 with a median survival of 10.2 months could be further classified according to VISUM-HCC criteria into

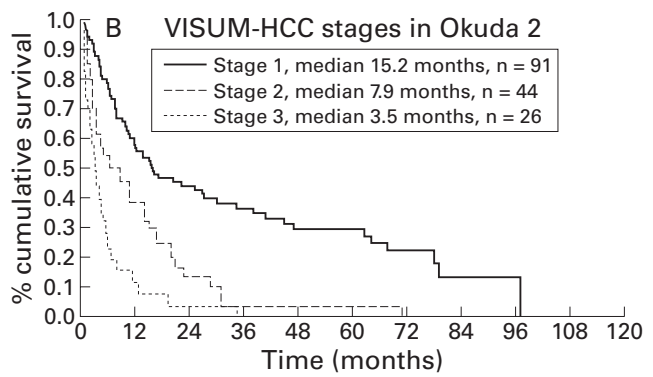

Figure 4 (A) Okuda stage 2, (B) Okuda stage 2 grouped according to VISUM-HCC; significantly different survival rates were noted between stages 1,2 , and 3 . 
groups with median survival of 15.2 months, 7.9 months, and 3.5 months, respectively. Okuda stages 1 and 3 could not be further subdivided by applying VISUM criteria.

\section{Discussion}

This study reports the results of a large single institution series on prognostic features and survival of patients with HCC in Central Europe. Based on univariate and multivariate analysis of clinical variables, a new survival model (Vienna survival model for HCC, VISUM-HCC) was characterised and tested on an independent group of patients. The new VISUM-HCC survival model may be useful for stratifying patients with HCC for clinical treatment modalities.

In our series, as in others, ${ }^{27}$ the diagnosis of HCC was made at an advanced stage of the disease. Only $16 \%$ were in Okuda stage 1 and almost all patients were either TNM stage 3 or 4. This is more advanced than in reports from other Western countries showing $52 \%{ }^{28}$ and $57 \%^{29}$ in Okuda stage 1 or $18 \%$ in stage 1 or 2 according to TNM classification. ${ }^{30}{ }^{31}$ The indolent nature of the disease in the early stages, lack of an institutionalised screening programme for HCC in liver cirrhosis, and a low index of suspicion in a region of low prevalence of HCC in the general population may explain these differences. In addition, our referral centre evaluates many HCC patients for liver transplantation and performs staging aggressively. This may have produced a shift towards higher stages of HCC. Due to the referral bias, our HCC population may therefore be skewed towards more advanced tumour stages and lower median survival.

The overall median survival of 8.0 months in our patients was similar to other studies with median survival times of 2.1-10.0 months. ${ }^{30}$ 32-37 In patients with liver cirrhosis, Child-Pugh stage has a predominant influence on survival time. ${ }^{28}$ The importance of liver function is also underscored by our multivariate analysis in which two (bilirubin and PT) of the three most powerful independent prognostic factors were parameters of liver function. The best predictive parameter relating to tumour was the presence or absence of PVT whereas tumour mass $>50 \%$, enlarged lymph nodes, or AFP $>180 \mu \mathrm{g} / 1$ were of less significance. The independent prognostic factors in our patient population were similar but not completely identical to the findings of others. ${ }^{30} 38$ In all studies bilirubin was an important parameter. In contrast with other reports, ${ }^{30}{ }^{38}$ low albumin was not predictive of survival. Similarly, the role of alkaline phosphatase, ${ }^{39}$ tumour size, ${ }^{235}$ PVT, ${ }^{39}$ ascites, ${ }^{235} \mathrm{AFP}^{40}$ and metastases ${ }^{35}$ were conflicting and may reflect the heterogeneity of the patient population.

A simplified survival model (VISUM-HCC) was then constructed by assigning 0 (absent) or 1 (present) to the six significant variables (bilirubin $(<2 \mathrm{mg} / \mathrm{dl}), \mathrm{PT}(<70 \%)$, PVT, AFP $(\leqslant 180 \mu \mathrm{g} / \mathrm{l})$, tumour size $>50 \%$ of liver mass, and enlarged lymph nodes) identified in the multivariate analysis. The score separates three prognostic stages with different median sur- vival times of 15.2, 7.2, and 2.6 months, respectively. Assignment of patients to one of the three prognostic stages provides clinically valuable information for the management of patients. Patients in VISUM-HCC stage 3 (with a median survival of 2.6 months) may not be considered for active treatment but rather be offered supportive care. In contrast, patients in VISUM-HCC stage 1 (with a median survival of 15.2 months) may benefit from surgical or non-surgical procedures.

Validation of a prognostic model is usually done by applying the model's coefficients to an independent group of patients. In many reports ${ }^{35}{ }^{39}$ the split sample technique is used by randomly assigning patients of the whole group to subgroups used to construct the model and to another subgroup on which the model is validated. Thus both groups belong to the same patient population and have similar risk factors. However, a truly independent group is preferable for validation. Our testing group consisted of 89 patients with HCC who were referred to our department in the years after the patients in the model group.

Various prognostic models have been developed for HCC. ${ }^{235} 39{ }^{41-44}$ We applied the staging models proposed by Okuda and UICC to our patients. In both models significant differences in survival between disease stages were found; however, both models had clear limitations when applied to our patients. In Okuda's model there was no significant survival difference between stages 1 and 2 . The 95\% confidence interval between stage 1 and stage 2 showed considerable overlap. In the VISUMHCC model, prognostic stages 1, 2, and 3 were clearly separated with almost no overlap. UICC's TNM classification is of limited clinical usefulness because only a few patients were in stage 1 or 2 and the difference in survival between stages 3 and 4 was small. ${ }^{3} 3038394546$ TNM classification was less effective than Child's classification in patients with HCC and liver cirrhosis, which again underscores the important impact of liver function on survival.

The clinical management of patients in Okuda stage 1 is surgery such as liver resection or liver transplantation. In contrast, patients in Okuda stage 3 should receive only supportive care. The best treatment for patients in Okuda stage 2 is unclear and needs to be studied in randomised clinical trials. The large variation in the prognosis of patients in Okuda stage 2 makes clinical studies difficult to perform. The VISUM-HCC model can be used to design treatment trials in a more homogeneous patient population. This strategy identifies on the one hand patients in Okuda stage 2 with survival similar to Okuda stage 1 patients and on the other Okuda stage 2 patients with survival as poor as Okuda stage 3 patients. The recently developed CLIP score ${ }^{43}$ includes similar parameters as our model and can better characterise patients in the intermediate Okuda stage. The BCLC staging classification $^{44}$ uses different parameters than our VISUM-HCC staging classification.

In conclusion, Austrian patients with HCC had a poor median survival of eight months. Six 
easily measurable clinical variables were identified as significant predictors of survival in these patients. The VISUM-HCC model, including both liver function parameters and tumour characteristics, may be useful for stratifying patients with HCC for various clinical treatment modalities.

We thank Ms A Kaider for valuable statistical advice.

1 El-Serag HB, Mason AC. Rising incidence of hepatocellular carcinoma in the United States. $N$ Engl $f$ Med 1999;340:745-50.

2 Okuda K, Ohtsuki T, Obata H, et al. Natural history of hepatocellular carcinoma and prognosis in relation to

3 Izumi R, Shimizu K, Tohru II, et al. Prognostic factors of hepatocellular carcinoma in patients undergoing hepatic hepatocellular carcinoma in patients undert
resection. Gastroenterology 1994;106:720-7.

4 Stroffolini T, Andreone P, Andriulli A, et al. Charcteristics of hepatocellular carcinoma in Italy. $\mathcal{F}$ Hepatol 1998;29. 944-52.

5 Bianchi P, Bianchi-Porro G, Coltorti M, et al. Occurrence of Australian antigen in chronic hepatitis in Italy. Gastroenterology 1972;63:482-5.

6 De Bac C, Stroffolini T, Gaeta GB, et al. Pathogenic factors in cirrhosis with and without hepatocellular carcinoma: a multicenter Italian study. Hepatology 1994;20:1125-30.

7 Simonetti RG, Camma C, Fiorello F, et al. Hepatocellular carcinoma: a worldwide problem: the major risk factors. Dig Dis Sci 1991;36:962-72.

8 Lunn RM, Zhang YJ, Wang LY, et al. p53 mutations, chronic hepatitis $\mathrm{B}$ virus infection, and aflatoxin exposure in hepatocellular carcinoma in Taiwan. Cancer Res 1997;57: in hepatoce.

9 Montesano R, Hainaut P, Wild CP. Hepatocellular carcinoma: from gene to public health. $\mathcal{F}$ Natl Cancer Inst 1997;89:1844-51.

10 Di Bisceglie A, Rustgi V, Hoofnagle J, et al. NIH conference. Hepatocellular carcinoma. Ann Intern Med 1998;108:390401.

11 Parkin DM, Whelan S, Ferlay SL, et al. Cancer incidence in five continents, vol VII. Lyon: IARC Sci Public No. 142, 1997.

12 Mor E, Kaspa RT, Sheiner P, et al. Treatment of hepatocellular carcinoma associated with cirrhosis in the era of liver transplantation. Ann Intern Med 1998;129:643-53.

13 Que FG, Nagorney DM. Hepatocellular carcinoma: a western perspective. Dig Surg 1995;12:45-52.

14 Zhao-You Tang. Treatment of hepatocellular carcinoma. Digestion 1998;59:556-62.

15 Kang JY, Guan R. Early detection of hepatocellular carcinoma. Dig Surg 1995;12:79-84.

16 Edmondson HA, Steiner PE. Primary carcinoma of the liver: a study of 100 cases among 48.900 necropsies. Cancer liver: a study of 100

17 Spiessl B, Beahrs OH, Hermanek P, et al. Liver. In: Spiessl B, Beahrs OH, Hermanek P, et al, eds. TNM atlas: illustrated guide to the TNM/pTNM classification of malignant tumors. New York: Springer-Verlag, 1989:98-105

18 Dorfman RE, Alpern MB, Gross BH, et al. Upper abdominal lymph nodes: criteria for normal size determined with CT. Radiology 1991;180:319-22.

19 Dusheiko GM, Hobbs KEF, Dick R, et al. Treatment of small hepatocellular carcinomas. Lancet 1992;340:285-8.

20 Bruix J. Treatment of hepatocellular carcinoma. Hepatology 1997;25:259-62.

21 Trinchet JC, Beaugrand M. Treatment of hepatocellular carcinoma in patients with cirrhosis. F Hepatol 1997;27: 756-65.

22 Kaplan EL, Meier P. Nonparametric estimation from incomplete observations. f Am Stat Assoc 1958;53:457-81.
23 Cox DR. Regression models and life tables (with discussion). FR Stat Soc B 1972;34:187-220.

24 Christensen E. Multivariate survival analysis using Cox's regression model. Hepatology 1987;7:1346-55.

25 Kalbfleisch JB, Prentice RC. The statistical analysis of failure time data. New York: Wiley, 1980.

26 Gines P, Quintero E, Arroyo V, et al. Compensated cirrhosis: natural history and prognostic factors. Hepatology 1987;7: $122-8$.

27 Collier JD, Curless R, Bassendine MF, et al. Clinical features and prognosis of hepatocellular carcinoma in Britain in relation to age. Age Ageing 1994;23:22-7.

28 Markovic S, Gadzijev E, Stabuc B, et al. Treatment options in Western hepatocellular carcinoma: a prospective study of 224 patients. Hepatology 1998;29:650-9

29 Petry W, Heintges T, Hensel F, et al. Hepatozelluläres Karzinom in Deutschland. Epidemiologie, Ätiologie, Klinik und Prognose bei 100 konsekutiven Patienten einer Universitätsklinik. Z Gastroenterol 1997;35:1059-69.

30 Stuart KE, Anand AJ, Jenkins RL. Hepatocellular carcinoma in the United States: Prognostic features, treatment outcome and survival. Cancer 1996;77:2217-22.

31 Collier JD, Curless R, Bassendine MF, et al. Clinical features and prognosis of hepatocellular carcinoma in Britin in relation to age. Age Ageing 1994;23:22-7.

32 Colombo M, de Franchis R, Del Nino E, et al. Hepatocellular carcinoma in Italian patients with cirrhosis. $N$ Engl $\mathcal{F}$ Med 1991;325:675-80.

33 Bismuth H, Morino M, Sherlock D, et al. Primary treatment of hepatocellular carcinoma by arterial chemoembolization. Am f Surg 1992;163:387-94.

34 Falkson G, Cnaan A, Schutt AS, et al. Prognostic factors for survival in hepatocellular carcinoma. Cancer Res 1988;48: 7314-18.

35 Calvet X, Bruix J, Gines P, et al. Prognostic factors of hepatocellular carcinoma in the West: a multivariate analysis in 206 patients. Hepatology 1990;12:753-60.

36 Stuart K, Jenkins R, Trey C, et al. Treatment of hepatocelluar carcinoma using doxorubicin/ethiodized oil/gelatin powder chemoembolization. Cancer 1993;72:3202-9.

37 Paterlini P, Driss F, Nalpas B, et al. Persistance of hepatitis $\mathrm{B}$ and hepatitis $\mathrm{C}$ viral genomes in primary liver cancers rom HbsAg-negative patients: a study of a low endemic area. Hepatology 1993;17:20-9.

38 Pawarode A, Voravud N, Sriuranpong V, et al. Natural history of untreated primary hepatocellular carcinoma: a retrospective study of 157 patients. Am f Clin Oncol 1998. 21:386-91.

39 Chevret S, Trinchet J-C, Mathieu D, et al. A new prognostic classification for predicting survival in patients with hepatocellular carcinoma. F Hepatol 1999;31:133-41.

40 Nomura F, Ohmishi K, Tanabe Y. Clinical factors and prognosis of hepatocellular carcinoma with reference to serum alphafetoprotein levels. Analysis of 606 patients. Cancer 1989;64:1700-7.

41 Okada S, Okazaki N, Nose H, et al. Prognostic factors in patients with hepatocellular carcinoma receiving systemic chemotherapy. Hepatology 1992;16:112-17.

42 Akashi Y, Koreeda C, Enomoto S, et al. Prognosis of unresectable hepatocellular carcinoma. An evalulation based on multivariate analysis of 90 cases. Hepatology 1991;14: $262-8$.

43 The cancer of the liver Italian program investigators. A new prognostic system for hepatocellular carcinoma: a retrospective study of 435 patients. Hepatology 1998;28:751-5.

44 Llovet JM, Bru C, Bruix J. Prognosis of hepatocellular carcinoma: the BCLC staging classification. Semin Liver Dis 1999;19:329-38.

45 Ringe B, Pichlmayr R, Wittekind C, et al. Surgical treatment of hepatocellular carcinoma: experience with liver resection and transplantation in 198 patients. World F Surg 1991;15: 270-85.

46 Iwatsuki S, Starzl TE, Sheahan DG, et al. Hepatic resection versus transplantation for hepatocellular carcinoma. Ann Surg 1991;214:221-9. 